Supporting Information:

\title{
Hydrolytic Activation Kinetics of the Herbicide Benzobicyclon in Simulated
}

\section{Aquatic Systems}

\author{
Katryn L Williams ${ }^{a *}$ and Ronald S Tjeerdema ${ }^{a}$ \\ ${ }^{a}$ Department of Environmental Toxicology, College of Agricultural and Environmental \\ Sciences, University of California, Davis, CA, USA
}

*Tel: 530-752-2534. E-mail: katwilliams@ucdavis.edu

Mailing address: One Shields Avenue, Davis, California

ZIP code 95616

Page S2: Description of statistical analysis

Page S3: Figure S1. Arrhenius plots for all treatments.

Page S4: Table S1. Extraction recoveries for BZB and BH from SPE (expressed as a percent). SE denotes standard error of the mean $(n=5)$.

Number of pages: 4

Number of figures: 1

Number of tables: 1 


\section{Statistical Analysis}

Data satisfied the assumption of normality via the Shapiro-Wilk test, however data were shown to be heteroscedastic using Levene's test. Therefore, a weighted-least squares ANOVA was weighted using the reciprocal of the stratified variances of the most significant effect in the Levene's analysis, which was aqueous treatment. To account for differing time points throughout the experiment, one value were chosen to represent the same time point for all temperatures and treatments. A separate variable $(\Delta t)$ was designated as the difference between the individual time points and their respective normalized time points. The ANOVA factorial model was run with normalized time points, temperature, and aqueous treatment as nominal predictors, and with $\Delta \mathrm{t}$ as a covariate. This allowed for the analysis of temporal effects without requiring the assumption that the effects were linear while adjusting for changes in sampling times. 

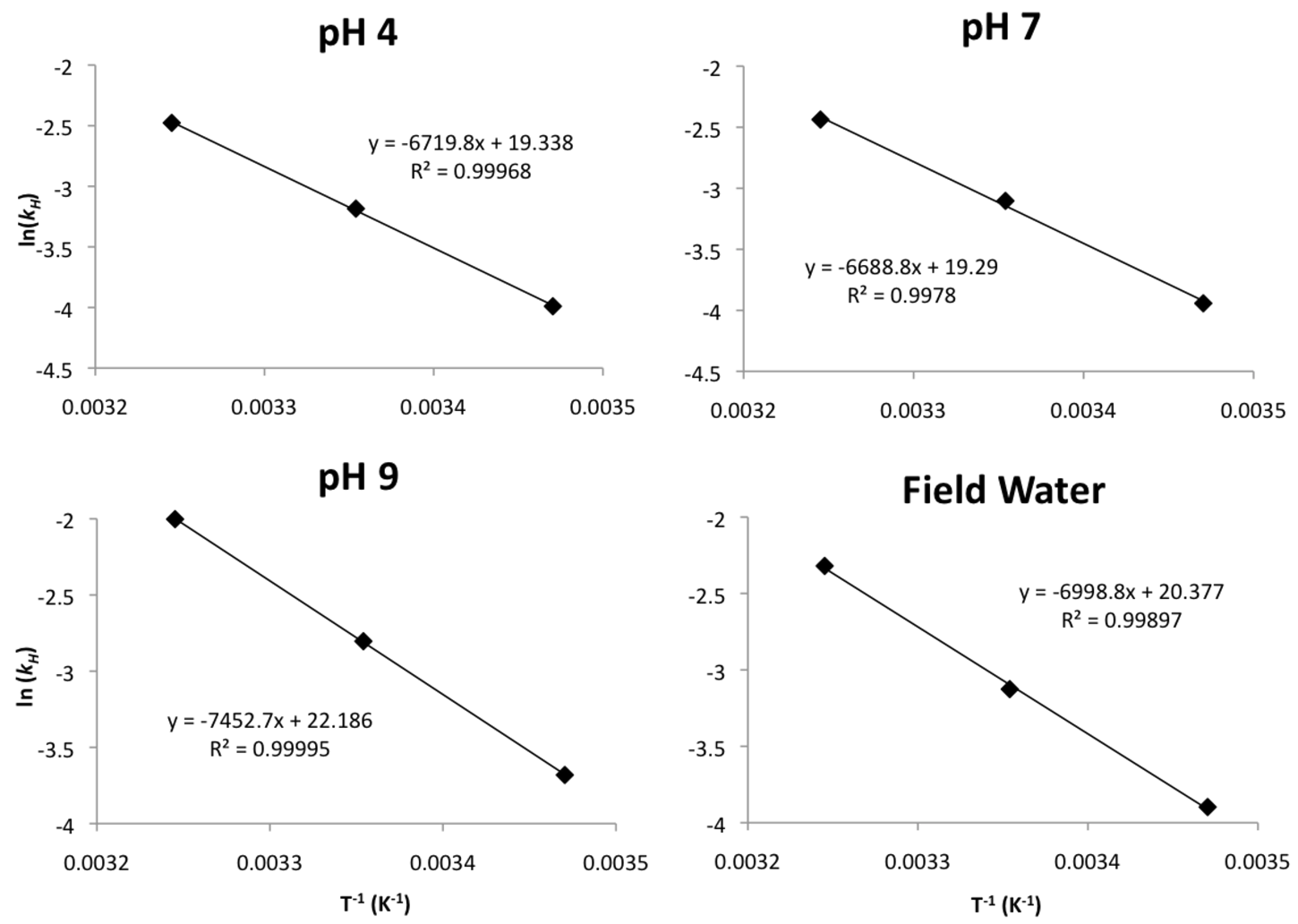

Figure S1. Arrhenius plots for all treatments. 
Table S1. Extraction recoveries for BZB and BH from SPE (expressed as a percent). SE denotes standard error of the mean $(n=5)$.

\begin{tabular}{|c|c|c|c|}
\hline $\begin{array}{l}\text { Aqueous } \\
\text { Treatment }\end{array}$ & Concentration & $\begin{array}{c}\text { BZB } \\
\text { Percent Recovery }( \pm \text { SE) }\end{array}$ & $\frac{\text { BH }}{\text { Percent Recovery }( \pm \text { SE) }}$ \\
\hline \multirow{2}{*}{$\mathrm{pH} 4$} & $0.025 \mathrm{mg} / \mathrm{L}$ & $105.6( \pm 2.5)$ & $110.1( \pm 2.7)$ \\
\hline & $0.005 \mathrm{mg} / \mathrm{L}$ & $100.3( \pm 6.3)$ & $82.8( \pm 5.4)$ \\
\hline \multirow{2}{*}{$\mathrm{pH} 7$} & $0.025 \mathrm{mg} / \mathrm{L}$ & $111.3( \pm 2.6)$ & $113.7( \pm 4.7)$ \\
\hline & $0.005 \mathrm{mg} / \mathrm{L}$ & $129.1( \pm 5.9)$ & $109.4( \pm 5.6)$ \\
\hline \multirow{2}{*}{$\mathrm{pH} 9$} & $0.025 \mathrm{mg} / \mathrm{L}$ & $112.9( \pm 3.7)$ & $112.1( \pm 2.5)$ \\
\hline & $0.005 \mathrm{mg} / \mathrm{L}$ & $109.0( \pm 8.1)$ & $87.1( \pm 3.9)$ \\
\hline \multirow{2}{*}{ Field } & $0.025 \mathrm{mg} / \mathrm{L}$ & $100.9( \pm 5.8)$ & $104.2( \pm 6.9)$ \\
\hline & $0.005 \mathrm{mg} / \mathrm{L}$ & $118.1( \pm 10.0)$ & $159.0( \pm 7.9)$ \\
\hline
\end{tabular}

